\title{
Stage III thymoma: Relationship of local invasion to recurrence
}

\author{
Tomoki Utsumi, MD, PhD, ${ }^{a}$ Hiroyuki Shiono, MD, PhD, ${ }^{a}$ Akihide Matsumura, MD, PhD, ${ }^{\mathrm{b}}$ Hajime Maeda, $\mathrm{MD}, \mathrm{PhD},{ }^{\mathrm{c}}$ \\ Mitsunori Ohta, MD, PhD, ${ }^{\mathrm{d}}$ Hirohito Tada, MD, $\mathrm{PhD},{ }^{\mathrm{e}}$ Akinori Akashi, MD, $\mathrm{PhD},{ }^{\mathrm{f}}$ and Meinoshin Okumura, MD, $\mathrm{PhD}^{\mathrm{a}}$
}

Objectives: We investigated the relationships of recurrence site with the involved organ and cell type in patients with Masaoka stage III thymomas.

\begin{abstract}
Methods: Records of 84 patients who underwent a complete resection of stage III thymomas between 1957 and 2005 were reviewed and then divided according to involved organ. The number of patients with cell types determined according to World Health Organization criteria were 2, 5, 7, 37, and 7 for types A, AB, B1, B2, and B3, respectively, whereas type was not determined in 25 patients.

Results: Lung invasion occurred in 58 patients, followed by invasion of the pericardium in 47 and invasion of the great vessels in 23. Recurrence occurred in 23 patients, which included 12 with pleural dissemination and 8 with distant metastasis, mostly in the lung. Lung invasion was seen in 8 of the 12 patients with pleural recurrence, whereas vascular invasion was seen in 6 of the 8 patients with distant metastasis. Local recurrence was less common. Disease-free survival after 10 years for all subjects was $74.2 \%$, whereas it was lower for those with vascular invasion $(46.1 \%)$ compared with those without invasion $(87.1 \%, P<.05)$. Of the 23 patients with recurrence, World Health Organization cell types B1, B2, and B3 were seen in 2, 11, and 3 cases, respectively, whereas type was not determined in 7 patients.

Conclusions: The pleural cavity and lung are common sites of recurrence of Masaoka stage III thymomas. It is important to establish an inclusive therapeutic strategy that considers the relationships of involved organs and sites of recurrence in these patients.
\end{abstract}

The clinical classification system of thymomas proposed by Masaoka and associates ${ }^{1}$ has long been used as a prognostic factor for patients with thymomas. Since surgical resection has taken a pivotal role in the treatment of thymomas, various investigations of the outcome of patients after resection have been conducted to evaluate that treatment. Those studies have shown that the survival rate for patients with Masaoka stage I and II thymomas is greater than $80 \%$ at 10 to 20 years. ${ }^{2-8}$ In contrast, the 10 -year survival rate for patients with stage III disease in previous studies ranges from $30 \%$ to $85 \%$, whereas it is lower than $58 \%$ in patients with stage IV disease. These results indicate that new therapeutic strategies should be developed to improve the outcome of patients with thymomas in those advanced stages. After reporting that patients with stage III disease and in-

From the Department of General Thoracic Surgery, ${ }^{a}$ Osaka University Graduate School of Medicine, Suita, Japan; the Department of Surgery, ${ }^{\mathrm{b}}$ National Kinki-Chuo Center for Thoracic Diseases, Sakai, Japan; the Department of Surgery, ${ }^{\mathrm{c}}$ National Toneyama Hospital, Toyonaka, Japan; the Department of General Thoracic Surgery, ${ }^{\mathrm{d}}$ Osaka Prefectural Center for Respiratory Diseases and Allergy, Habikino, Japan; the Department of Surgery, ${ }^{\mathrm{e}}$ Osaka General Hospital, Osaka, Japan; and the Department of General Thoracic Surgery, ${ }^{\mathrm{f}}$ Takarazuka Municipal Hospital, Takarazuka, Japan.

Read in part at the Twenty-fourth Annual Meeting of the Japan Association for Chest Surgeons, Yokohama, Japan, May 17-19, 2007.

Received for publication Dec 30, 2007; revisions received April 17, 2008; accepted for publication May 4, 2008.

Address for reprints: Meinoshin Okumura, MD, PhD, Department of General Thoracic Surgery, Osaka University Graduate School of Medicine, 2-2, Yamadaoka, L-5,

Suita-City, Osaka 565-0871, Japan (E-mail: meinosin@surg1.med.osaka-u.ac.jp). J Thorac Cardiovasc Surg 2008;136:1481-5

$0022-5223 / \$ 34.00$

Copyright (C) 2008 by The American Association for Thoracic Surgery

doi:10.1016/j.jtcvs.2008.05.012 volvement of the great vessels had shorter disease-specific survival compared with those without involvement, ${ }^{9}$ we considered that the site of recurrence is important for treatment of patients with advanced stage thymomas, and elucidation of those sites as related to involved organs might contribute to improving the survival rate.

We previously reported that the histologic classification system of thymomas proposed by the World Health Organization $(\mathrm{WHO})^{10}$ was a significant prognostic factor for patients with thymomas in addition to Masaoka clinical staging, ${ }^{3}$ after which a number of authors confirmed our findings with their patient data. ${ }^{4,6,7,11-13}$ In the present study we examined the relationships of the site of recurrence with the involved organs and with WHO histologic classification.

\section{MATERIALS AND METHODS}

We reviewed the records of 346 patients who underwent complete resection for a thymoma at Osaka University Hospital and its affiliated hospitals during the 48-year period from 1957 to 2004. Patients with a final diagnosis of thymic carcinoma and those who underwent a biopsy alone, as well as those who received a resection with a macroscopic or microscopic residual tumor, were not included. Of these 346 patients, 84 were classified as having stage III disease in Masaoka's staging system ${ }^{1}$ and were selected for the present study. The subjects comprised 49 male and 35 female patients, who ranged in age from 20 to 83 years (mean, 51 years). Chemotherapy was administered in 16 patients: 8 preoperatively and 8 postoperatively. Radiation therapy was performed in 64 patients: 9 preoperatively, 55 postoperatively, and 1 both preoperatively and postoperatively.

The involved organs were determined after a critical review of the operative records, and involvement of the great vessels $(\mathrm{V})$, lungs $(\mathrm{L})$, and pericardium $(\mathrm{P})$ was evaluated. Thus a total of 7 groups of subjects were generated: $\mathrm{V}(+) \mathrm{L}(+) \mathrm{P}(+), \mathrm{V}(+) \mathrm{L}(+) \mathrm{P}(-), \mathrm{V}(+) \mathrm{L}(-) \mathrm{P}(+), \mathrm{V}(-) \mathrm{L}(+) \mathrm{P}(+)$, $\mathrm{V}(+) \mathrm{L}(-) \mathrm{P}(-), \mathrm{V}(-) \mathrm{L}(+) \mathrm{P}(-)$, and $\mathrm{V}(-) \mathrm{L}(-) \mathrm{P}(+)$, where $(+)$ indicates existence 


$$
\begin{aligned}
& \text { Abbreviations and Acronyms } \\
& \begin{aligned}
\mathrm{L} & =\text { lungs } \\
\mathrm{P} & =\text { pericardium } \\
\mathrm{V} & =\text { great vessels } \\
\mathrm{WHO} & =\text { World Health Organization }
\end{aligned}
\end{aligned}
$$

of involvement and (-) indicates no involvement. For analyzing disease-free survival, the subjects were assigned to one of 3 groups, $\mathrm{V}(+) \mathrm{L}(+$ or -$) \mathrm{P}(+$ or -$), \mathrm{V}(-) \mathrm{L}(+) \mathrm{P}(+$ or -$)$, and $\mathrm{V}(-) \mathrm{L}(-) \mathrm{P}(+)$ because some groups had too few members to effectively perform a statistical analysis.

There were no strict rules for postoperative follow-up; however, it was common to obtain computed tomograms of the chest once a year. In the era before computed tomography was available, chest radiographic analysis was performed once or twice a year. Recurrence was diagnosed based on imaging or pathologic examinations by reviewing the subject records. When recurrence was detected at multiple sites, each was recorded as such. The interval between resection of the thymoma and detection of recurrence was calculated. When a patient died of other diseases than thymoma, he or she was treated as a censored case at the time of death.

Pathologic examinations were performed with hematoxylin and eosinstained sections derived from paraffin-embedded blocks. Histologic diagnosis with reference to the WHO classification system was performed to distribute the cases into cell types $\mathrm{A}, \mathrm{AB}, \mathrm{B} 1, \mathrm{~B} 2$, and $\mathrm{B} 3$, and then recurrence rates with reference to the WHO cell types were determined. The relationships between the WHO cell type and involved organs and between cell type and interval from resection to recurrence were also examined.

Recurrence rates were compared among each group by using a $\chi^{2}$ test. Actuarial disease-free survival rates were calculated with the Kaplan-Meier method, and statistical differences between survival curves were examined with a log-rank test. In case there were 3 or more groups to be compared, a multiple comparison test was performed. Statistical analyses were performed with the personal computer software StatView 5 (SAS Institute, Inc, Cary, NC).

\section{RESULTS}

The number of patients in each category of involved organs is indicated in Table 1 . Among the 84 patients, invasion into the great vessels, lungs, and pericardium was seen in 23 , 58 , and 47 patients, respectively, including duplication. Furthermore, invasion into 1,2, and 3 organs was seen in 48, 25, and 10 patients, respectively. In the 23 patients with invasion into the great vessels, sites of invasion included the left innominate vein, the superior vena cava, or both. Invasion into the aorta was seen in 2 patients, and in both it remained at the adventitia. In the 58 patients with lung invasion, wedge resections were performed for all but one.

Tumor recurrence occurred in 23 of 84 patients. A review of recurrence rates according to the presence or absence of involvement of each category of organs showed 12 recurrences in the 23 cases that involved the great vessels $(52.2 \%)$, whereas there were 11 recurrences in 61 patients without that involvement $(18.3 \%, P=.002)$. In the same manner, 17 recurrences were found in the 58 patients with lung involvement $(29.3 \%)$, whereas 6 were found in the

\begin{tabular}{|c|c|c|c|c|}
\hline \multicolumn{3}{|c|}{ Involved organs } & \multirow[b]{2}{*}{ n (recurrence) } & \multirow[b]{2}{*}{ Patterns (n) } \\
\hline $\mathbf{V}$ & $\mathbf{L}$ & $\mathbf{P}$ & & \\
\hline+ & + & + & $10(5)$ & PD (4), lung (1) \\
\hline+ & + & - & $5(2)$ & Lung + local (1), brain (1) \\
\hline+ & - & + & $4(3)$ & $\begin{array}{l}\text { Lung (2) PD + liver }+ \\
\text { local (1) }\end{array}$ \\
\hline- & + & + & $16(1)$ & Pericardial dissemination \\
\hline+ & - & - & $4(2)$ & PD + local (1), PD (1) \\
\hline- & + & - & $27(9)$ & $\begin{array}{l}\text { PD (4), PD + local (1), } \\
\text { lung (2), local (1) }\end{array}$ \\
\hline- & - & + & $17(1)$ & Local (1) \\
\hline \multicolumn{3}{|c|}{ Not recorded } & 1 & \\
\hline \multicolumn{3}{|c|}{ Total } & $84(23)$ & \\
\hline
\end{tabular}
26 patients without involvement $(23.1 \%, P=.55)$, and 10 recurrences were found in the 47 patients with pericardial in-
TABLE 1. Involved organs and patterns of recurrence of Masaoka's stage III thymomas

$V$, Great vessels; $L$, lungs; $P$, pericardium; +, existence of involvement;-, nonexistence of involvement; $P D$, pleural dissemination.

volvement $(21.3 \%)$, whereas 13 were found in the $37 \mathrm{pa}-$ tients without involvement $(35.1 \%, P=.16)$.

The patterns of recurrence were pleural dissemination in 12 , distant metastases in 8 , and local recurrence in 6 patients, including duplication. Organs with metastasis were the lung in 6 patients and in 1 patient each for the liver and brain. Among the 6 patients with local recurrence, 2 experienced local recurrence only, whereas the other 4 had pleural dissemination, distant metastasis, or both along with local recurrence.

The relationships between the involved organs when resected and the sites of recurrence were also analyzed. Among 8 cases that recurred as distant metastasis, involvement of the great vessels was seen in 6 , whereas the other 2 cases involved the lung, which was resected, and also recurred in the lung. On the other hand, of the 12 patients who had recurrence as pleural dissemination, involvement of the lung was seen in 9 patients, and the great vessels, with or without pericardial involvement, were involved in the other 3 patients.

Actuarial disease-free 10- and 20-year survival rates for the whole population were $74.6 \%$ and $58.7 \%$, respectively. Grouped disease-free survival curves divided by the involved organs are shown in Figure 1. The disease-free survival curves for the 4 groups with involvement of the great vessels were similar, regardless of whether additional organs were involved. In an analysis of the $\mathrm{V}(+) \mathrm{L}(+$ or -$) \mathrm{P}(+$ or -$)$, $\mathrm{V}(-) \mathrm{L}(+) \mathrm{P}(+$ or -$)$, and $\mathrm{V}(-) \mathrm{L}(-) \mathrm{P}(+)$ groups, the 20 -year disease-free survival rates were $46.1 \%, 53.4 \%$, and $93.3 \%$, respectively $(P=.0082)$. The differences in disease-free survival between the $\mathrm{V}(+) \mathrm{L}(+$ or -$) \mathrm{P}(+$ or -$)$ groups and the other groups were important $(P=.0078$ and .0270$)$, whereas that between the $\mathrm{V}(-) \mathrm{L}(+) \mathrm{P}(+$ or -$)$ and $\mathrm{V}(-) \mathrm{L}(-) \mathrm{P}(+)$ groups was not $(P=.2106)$.

Adjuvant radiation therapy was used in 19 of the 23 patients with involvement of the great vessels and 45 of the 61 patients without involvement $(P=.5672)$. Grouped 

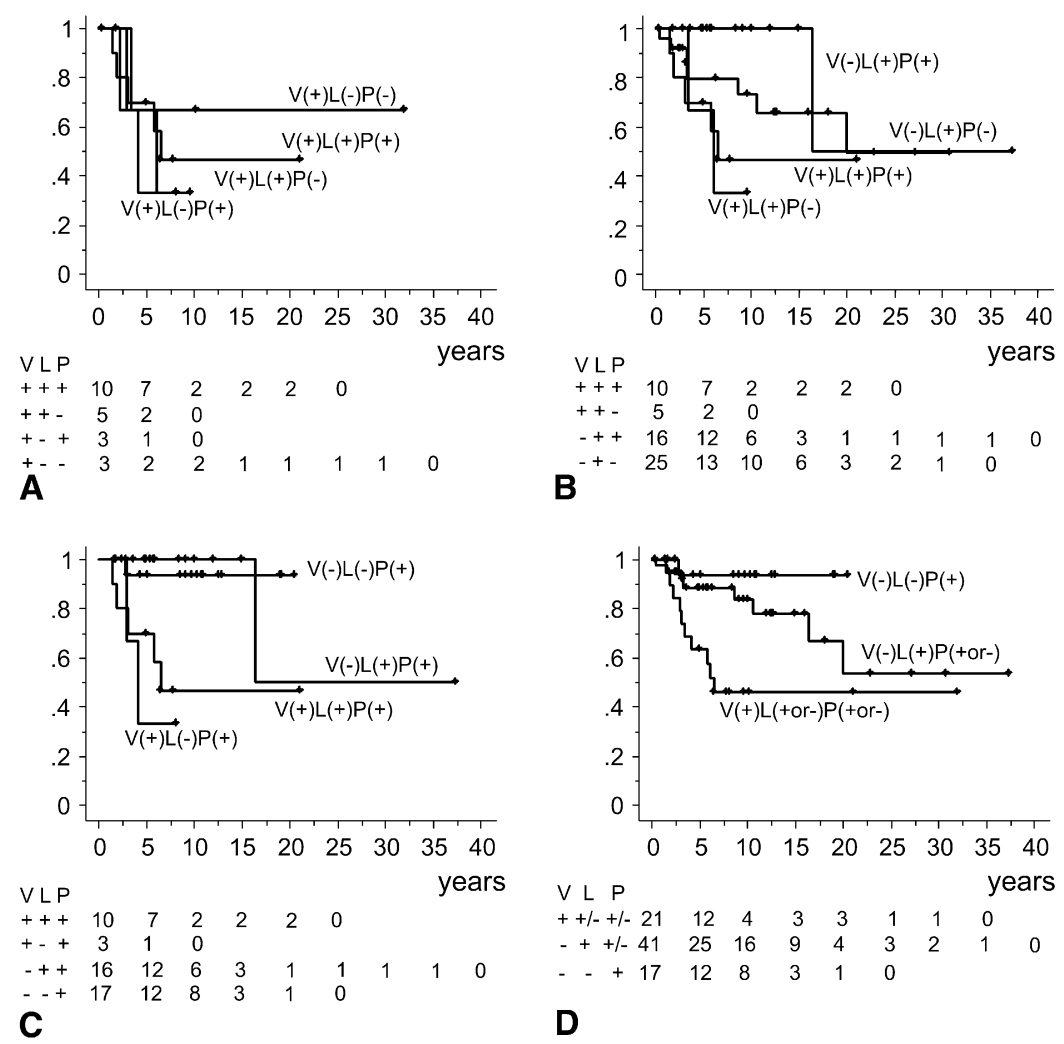

FIGURE 1. Actuarial survival curves of patients with involvement of the great vessels (A), lung (B), and pericardium (C), as well as for all patients (D). In each panel, +indicates cases with involvement of the specified organ,-indicates those without involvement, and + or-indicates those with and without such involvement. $V$, Great vessels; $L$, lung; $P$, pericardium.

20-year disease-free survival rates divided by the presence and the absence of radiation therapy were $54.4 \%$ for the former and $66.3 \%$ for the latter $(P=.9794)$. Local recurrence occurred in 5 patients in the former and 1 patient in the latter groups $(P>$.9999).

To examine the effect of long duration of the present study, the subjects were divided into one of 2 groups: one included those who underwent resection before $1990(n=41)$, and the other included those who underwent resection after $1991(\mathrm{n}=43)$. The 10-year disease-free survival rates were $78.4 \%$ and $67.5 \%$ for the former and the latter, respectively $(P=.4646)$. For those with involvement of the great vessels, they were $50.8 \%$ and $42.4 \%$, respectively $(P=.8582)$.

WHO cell type was identified in 58 patients (Table 2). The number of patients with type B2 cells had the greatest frequency (at $63.7 \%$ ) of cases with known WHO cell types, followed by types B1 and B3 (at 12.1\% each). Cell types $\mathrm{AB}$ and $\mathrm{A}$ were seen less commonly. Although the number of patients was small, there was no recurrence in patients with cell types $\mathrm{A}$ and $\mathrm{AB}$. The recurrence rates for cell types B1, B2, and B3 were $28.6 \%, 29.7 \%$, and $42.9 \%$, respectively, with the differences not important, whereas actuarial disease-free survival was also similar among patients with those 3 cell types $(P=.96$, Figure 2$)$.

\section{DISCUSSION}

There are several reports regarding thymoma recurrence. ${ }^{8,14,15}$ However, to the best of our knowledge, the present study is the first to focus on the relationships among involved organs and sites of recurrence.

In our series, pleural dissemination was the most frequent pattern of recurrence in Masaoka stage III thymomas, followed by distant metastasis. Many cases of recurrence in the pleura arose from those that originally showed involvement of the lung. The biologic mechanism by which pleural dissemination occurs more often than distant metastasis has yet to be clarified; however, previous studies of thymoma recurrence also noted that recurrence in the pleural cavity was seen the most often. ${ }^{8,14,15}$ As for the reason for frequent recurrence in the pleura, we considered that thymomas with lung invasion must pass through the mediastinal pleura while they grow to be exposed on the surface of the thoracic cavity and invade the lung because the thymus is originally located in the anterior mediastinum. Thus it is more likely that thymomas with involvement of the lung coexist with disseminated tumor cells in the thorax compared with those without thoracic exposure, even if the disseminated lesions cannot be seen by means of diagnostic imaging or macroscopic inspection at a thoracotomy. 
TABLE 2. Relationships of involved organs and WHO cell types and recurrence of Masaoka's stage III thymomas

\begin{tabular}{|c|c|c|c|c|c|c|c|c|c|}
\hline \multicolumn{3}{|c|}{ Involved organs } & \multicolumn{6}{|c|}{ WHO cell types } & \multirow[b]{2}{*}{ Total } \\
\hline $\mathbf{V}$ & $\mathbf{L}$ & $\mathbf{P}$ & $\mathbf{A}$ & $\mathbf{A B}$ & B1 & B2 & B3 & ND & \\
\hline+ & + & + & 1 & 1 & & $6(4)$ & & $2(1)$ & $10(5)$ \\
\hline+ & + & - & & & 1 & $2(1)$ & $1(1)$ & 1 & $5(2)$ \\
\hline+ & - & + & & 1 & & $1(1)$ & $1(1)$ & $1(1)$ & $4(3)$ \\
\hline- & + & + & & & 3 & $4(1)$ & 3 & 6 & $16(1)$ \\
\hline+ & - & - & & & & 1 & & $3(2)$ & $4(2)$ \\
\hline- & + & - & 1 & 1 & $1(1)$ & $15(4)$ & $1(1)$ & $8(3)$ & $27(9)$ \\
\hline- & - & + & & 2 & $2(1)$ & 8 & 1 & 4 & $17(1)$ \\
\hline Total & & & 2 & 5 & $7(2)$ & $37(11)$ & $7(3)$ & $25(7)$ & $83(23)$ \\
\hline
\end{tabular}

Numbers in brackets indicate the number of patients with recurrence. $W H O$, World Health Organization; $V$, great vessels; $L$, lungs; $P$, pericardium; $N D$, not determined; +, existence of involvement; -, nonexistence of involvement.

Distant metastasis often occurs in cases with involvement of the great vessels, most frequently in the lungs. It is likely that the lung is the nearest organ with a capillary system for tumor cells to encounter because the left innominate vein is the most common great vessel involved. It is understandable that tumor cells would pass through the superior vena cava, right atrium and ventricle, and pulmonary artery before being scattered in the pulmonary capillaries and become implanted there to grow as a metastatic lesion. Although it remains as speculation, it seems important to place more emphasis on detecting recurrent lesions in the thorax, rather than in the bone, brain, or abdomen, when performing follow-up examinations of patients.

The present study revealed that the recurrence rate was greater and disease-free survival shorter in cases involving the great vessels compared with those without that involvement. In addition, when the great vessels are not involved, disease-free survival was similar, regardless of involvement of the lung and pericardium. Therefore the presence or

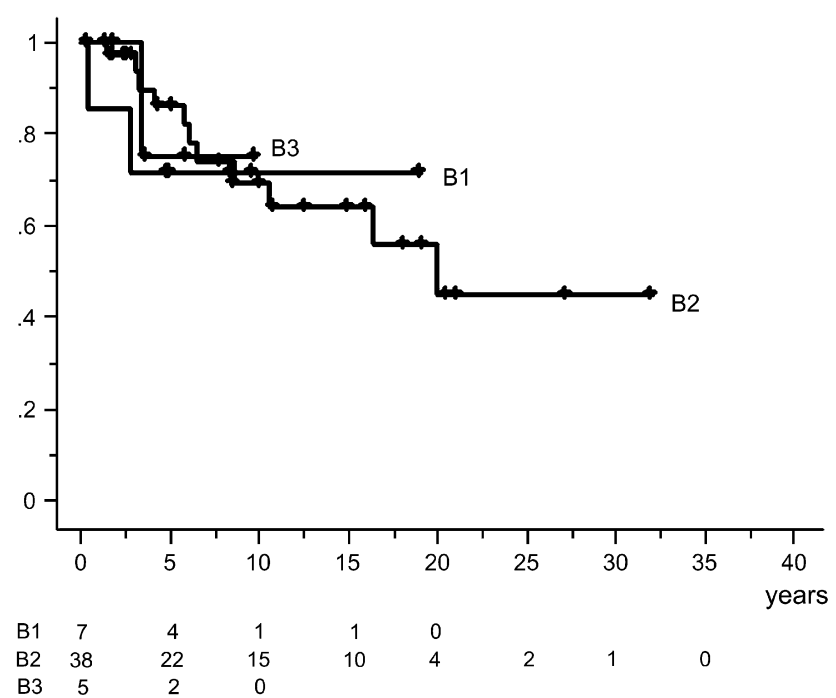

FIGURE 2. Actuarial survival curves of patients with WHO cell types B1, $\mathrm{B} 2$, and $\mathrm{B} 3$. absence of involvement of the great vessels might be of prognostic significance for determining the recurrence of thymomas. On the other hand, Wright and associates ${ }^{8}$ analyzed 179 thymic epithelial tumors, including 45 Masaoka stage III cases and 11 stage IV cases, and reported that the involved organ did not predict recurrence. We considered some possible reasons for this discrepancy. The patient population in their report included both those with thymomas and those with thymic carcinomas, whereas the present study focused exclusively on thymomas. This difference might have significantly affected the outcome of each study. It is also possible that the difference in the number of patients in both studies, which was greater in the present study, might have affected the statistical results. Based on these 2 reasons, both of which are important in regard to the study populations, we would suppose that the results in the present study compare favorably with those in the report of Wright and associates.

The pattern of recurrence for stage III thymomas found in the present study might affect the planning of adjuvant therapy for those patients. To date, postoperative radiation therapy to the mediastinum has been the most popular in our institution; however, local recurrence without pleural dissemination or distant metastasis was rare in the present study. Furthermore, perioperative radiation therapy did not have an effect on disease-free survival in our subjects, and the local recurrence rate for subjects with radiation therapy was the same as that for those without radiation therapy. Thus it seems reasonable to make use of systemic therapies rather than local ones to reduce the risk of pleural dissemination and distant metastases. On the other hand, patients with recurrent thymomas might benefit from re-resection. ${ }^{16}$ Therefore the significance of postoperative radiation therapy might require re-evaluation.

Recently, there have been reports describing that a multimodality therapy, including induction chemotherapy and surgical intervention with or without a postoperative therapy for stage III thymomas, might improve outcomes. ${ }^{17-19} \mathrm{We}$ found the subjects in the present study not appropriate for discussing the effect of induction chemotherapy because it 
was given only in the patients who were considered not resectable in the preoperative assessments. However, the significance of induction chemotherapy should be properly evaluated, especially in the patients with invasion into the great vessels because their prognoses were poor.

No recurrence was detected in patients with WHO cell types $\mathrm{A}$ and $\mathrm{AB}$, which is consistent with observations reported by Wright and associates. ${ }^{8}$ Furthermore, recurrence rates and disease-free survival were similar among cell types B1, B2, and B3. This result was somewhat unexpected because it has been generally accepted that WHO cell type is an independent prognostic factor for thymomas. Although our series of thymomas is likely the largest one studied to date, the number of patients is still insufficient to show statistical relevance, and another study conducted in a multiinstitutional setting might be required. Nevertheless, it is worthwhile to keep in mind, when following patients with Masaoka stage III thymomas, that cell types B1, B2, and B3 might represent a higher risk of recurrence compared with cell types $\mathrm{A}$ and $\mathrm{AB}$.

The limitations of the present study include its retrospective nature and the long duration of patient collection. Furthermore, developments of diagnostic techniques, such as computed tomography, and of surgical devices have caused changes in both the diagnosis and treatment of thymomas, which might have skewed the results of the present study.

In conclusion, pleural dissemination and lung metastasis were the 2 most frequent sites of recurrence in patients with completely resected stage III thymomas, and the site of recurrence was shown to be affected by the involved organs. Thus stage III thymomas are thought to include heterogenous subgroups, and an adjuvant treatment strategy for patients with these tumors should be determined by considering the involved organs.

We thank Dr Yuko Ohno of the Department of Health Promotion Science, Osaka University Graduate School of Medicine, Division of Health Sciences, for critical review of the manuscript, and advice on statistical issues.

\section{References}

1. Masaoka A, Monden Y, Nakahara K, Tanioka T. Follow-up study of thymomas with special reference to their clinical stages. Cancer. 1981;48:2485-92.
2. Regnard JF, Magdeleinat P, Dromer C, Dulmet E, de Montpreville V, Levi JF, et al. Prognostic factors and long-term results after thymoma resection: a series of 307 patients. J Thorac Cardiovasc Surg. 1996;112:376-84.

3. Okumura M, Ohta M, Tateyama H, Nakagawa K, Matsumura A, Maeda H, et al. The World Health Organization histologic classification system reflects the oncologic behavior of thymoma: a clinical study of 273 patients. Cancer. 2002;94: 624-32.

4. Chen G, Marx A, Wen-Hu C, Yong J, Puppe B, Stroebel P, et al. New WHO histologic classification predicts prognosis of thymic epithelial tumors: a clinicopath ologic study of 200 thymoma cases from China. Cancer. 2002;95:420-9.

5. Kondo K, Monden Y. Therapy for thymic epithelial tumors: a clinical study of 1,320 patients from Japan. Ann Thorac Surg. 2003;76:878-85.

6. Nakagawa K, Asamura H, Matsuno Y, Suzuki K, Kondo H, Maeshima A, et al. Thymoma: a clinicopathologic study based on the new World Health Organization classification. J Thorac Cardiovasc Surg. 2003;126:1134-40.

7. Rena O, Papalia E, Maggi G, Oliaro A, Ruffini E, Filosso P, et al. World Health Organization histologic classification: an independent prognostic factor in resected thymomas. Lung Cancer. 2005;50:59-66.

8. Wright CD, Wain JC, Wong DR, Donahue DM, Gaissert HA, Grillo HC, et al. Predictors of recurrence in thymic tumors: importance of invasion, World Health Organization histology, and size. J Thorac Cardiovasc Surg. 2005;130:1413-21.

9. Okumura M, Miyoshi S, Takeuchi Y, Yoon HE, Minami M, Takeda SI, et al. Results of surgical treatment of thymomas with special reference to the involved organs. J Thorac Cardiovasc Surg. 1999;117:605-13.

10. Travis WD, Brambilla E, Mueller-Hermelink HK, Harris CC. World Health Organization classification of tumours. pathology and genetics of tumours of the lung, pleura, thymus and heart. Lyon, France: IARC Press; 2004.

11. Kondo K, Yoshizawa K, Tsuyuguchi M, Kimura S, Sumitomo M, Morita J, et al WHO histologic classification is a prognostic indicator in thymoma. Ann Thorac Surg. 2004;77:1183-8.

12. Park MS, Chung KY, Kim KD, Yang WI, Chung JH, Kim YS, et al. Prognosis of thymic epithelial tumors according to the new World Health Organization histologic classification. Ann Thorac Surg. 2004;78:992-8.

13. Kim DJ, Yang WI, Choi SS, Kim KD, Chung KY. Prognostic and clinical relevance of the World Health Organization schema for the classification of thymic epithelial tumors: a clinicopathologic study of 108 patients and literature review. Chest. 2005;127:755-61.

14. Ruffini E, Mancuso M, Oliaro A, Casadio C, Cavallo A, Cianci R, et al. Recurrence of thymoma: analysis of clinicopathologic features, treatment, and outcome. J Thorac Cardiovasc Surg. 1997;113:55-63.

15. Haniuda M, Kondo R, Numanami H, Makiuchi A, Machida E, Amano J. Recurrence of thymoma: clinicopathological features, re-operation, and outcome. J Surg Oncol. 2001;78:183-8.

16. Okumura M, Shiono H, Inoue M, Tanaka H, Yoon HE, Nakagawa K, et al. Outcome of surgical treatment for recurrent thymic epithelial tumors with reference to world health organization histologic classification system. J Surg Oncol. 2007;95: 40-4.

17. Kim ES, Putnam JB, Komaki R, Walsh GL, Ro JY, Shin HJ, et al. Phase II study of a multidisciplinary approach with induction chemotherapy, followed by surgical resection, radiation therapy, and consolidation chemotherapy for unresectable malignant thymomas: final report. Lung Cancer. 2004;44:369-79.

18. Venuta F, Rendina EA, Longo F, Giacomo TD, Anile M, Mercadante E, et al. Long-term outcome after multimodality treatment for stage III thymic tumors. Ann Thorac Surg. 2003;76:1866-72.

19. Lucchi M, Melfi F, Dini P, Basolo F, Viti A, Givigliano F, et al. Neoadjuvant chemotherapy for stage III and IVA thymomas: a single-institution experience with a long follow-up. J Thorac Oncol. 2006;1:308-13. 